\title{
MICROCRÉDITO E TRABALHO NAS RUAS: desafios no contexto brasileiro
}

MICROCREDIT AND WORK ON THE STREETS: challenges in the Brazilian contexto

Patrícia Daniela Souza Anjos

PUC Minas

patriciasouzadosanjos@gmail.com

Marinette Santana Fraga

Universidade Federal de Juiz de Fora - campus Governador Valadares

marinettefraga@outlook.com

Armindo dos Santos de Sousa Teodósio

PPGA/PUC Minas

armindo.teodosio@gmail.com

Artigo aprovado na modalidade fast-track em parceria com o evento XI EGEPE 2020

\section{RESUMO}

Este artigo objetiva diagnosticar o perfil dos usuários de microcréditos nas principais instituições financeiras do Brasil para verificar se trabalhadores de rua como camelôs e vendedores ambulantes são alcançados por esse programa de inclusão financeira. Utilizou-se uma revisão bibliográfica sobre o trabalho informal e o microcrédito, com recorte em suas características condicionais e a focalização do público-alvo. Em sequência, procedeu-se à pesquisa secundária nos sites institucionais dos principais bancos públicos que disponibilizam serviços de microfinanças ou microcréditos. Os resultados mostraram a existência de poucas instituições de caráter público que oferecem microcréditos para trabalhadores de rua como ambulantes e camelôs informais ou formais. Além disso, há a hipótese de que grande parte desses trabalhadores desconhece o microcrédito. Para essa assertiva, recomendam-se pesquisas qualitativas de campo por meio de entrevistas a esse público.

PALAVRAS-CHAVE: Informalidade; Microcrédito; Ambulantes; Camelôs; Empreendedorismo por necessidade.

\section{ABSTRACT}

This article aims to diagnose the profile of microcredit users in the main financial institutions in Brazil to verify whether street workers such as street vendors and street vendors are reached by this financial inclusion program. A bibliographic review on informal work and microcredit was used, focusing on its conditional characteristics and focusing on the target audience. Subsequently, secondary research was carried out on the institutional websites of the main public banks that provide microfinance or microcredit services. The results showed the existence of few public institutions that offer microcredits to street workers such as street vendors and informal or formal street vendors. In addition, there is the hypothesis that most of 
these workers are unaware of microcredit. For this assertion, qualitative field research is recommended through interviews with this audience.

KEY-WORDS: Informality; Microcredit; Ambulantes; Camelôs; Entrepreneurship by necessity.

\section{INTRODUÇÃO}

Um dos cenários que mais tem chamado atenção nos centros das grandes capitais do Brasil é o aumento do número de pessoas trabalhando nas ruas. Os termos "trabalhador informal" e "trabalhador de rua" são utilizados, neste artigo, como abordagens equivalentes, designando, especificamente, os vendedores ambulantes e camelôs.

Pesquisas realizadas no Brasil apontaram que o aumento do trabalho nas ruas é justificado pela necessidade de sobrevivência e de gerar fontes alternativas de renda. Segundo dados da Pesquisa Nacional por Amostra de Domicílios Contínua (PNAD-IBGE, 2018), a taxa de desocupação caiu para 11,6\% no trimestre encerrado em novembro do ano de 2018. Todavia, a informalidade atingiu nível recorde na série histórica da pesquisa que foi iniciada em 2012. A maior parte das ocupações saiu do mercado de trabalho informal, no qual houve aumento de 528 mil pessoas trabalhando por conta própria e cerca de 498 mil empregados do setor privado sem carteira de trabalho. A pesquisa evidenciou que grande parte desse aumento está alinhada a trabalhos voltados para a sobrevivência, entre eles, as atividades de motorista de aplicativo, ambulantes e serviços de alimentação (IBGE, 2018).

Portanto, diversas pessoas recorrem à atividade informal por causa da dificuldade de reinserção no mercado de trabalho ou da necessidade de complementação de renda diante dos baixos níveis de assalariamento e de serviços precários. Dessa contextualização, emerge a possibilidade de disponibilização ou não de microcréditos aos trabalhadores/batalhadores de ruas, onde muitos vivem, inclusive, em situação de pobreza. Tais créditos são de pequenos valores e ofertados por algumas instituições financeiras visando possibilitar melhores condições de vida, mitigação da pobreza e atender aos objetivos internacionais de inclusão financeira.

Este artigo objetiva diagnosticar o perfil dos usuários de microcréditos nas principais instituições financeiras do Brasil para verificar se trabalhadores de rua como camelôs e vendedores ambulantes são alcançados por esse programa de inclusão financeira. Ter acesso aos créditos de pequenos valores e teoricamente de baixo custo ainda configura um embate, especialmente, para as pessoas inseridas na base da pirâmide.

Para a consecução de tal objetivo, foi realizado um levantamento teórico-conceitual, por meio da revisão bibliográfica, sobre o trabalho informal, dando ênfase às atividades praticadas nas ruas por vendedores ambulantes e camelôs. Posteriormente, as discussões abrangeram as principais características das políticas de microcrédito disponibilizadas e sua focalização no Brasil. Nas considerações finais, os autores instigam a realidade e a interface entre trabalhadores de rua e acesso financeiro, sendo este considerado uma alternativa para possibilitar o crescimento e expansão das atividades desses trabalhadores, melhores condições de vida e inclusão financeira sustentável.

\section{FUNDAMENTAÇÃO TEÓRICA}

\subsection{Perspectivas teóricas sobre o trabalho informal}


O crescente fenômeno da informalidade na hodiernidade abarca uma discussão não muito consensual entre economistas, sociólogos do trabalho, antropólogos e formuladores de políticas públicas, principalmente, no que tange à compreensão e elaboração de um conceito e teoria capaz de explicar as diferentes situações criadas por esse mercado nas economias mundiais, bem como quais consequências geram para a sociedade diante do cenário de mudanças estruturais econômicas, políticas e sociais. A maioria dos autores alegam que a atividade é precarizada, visto que os trabalhadores de ruas, muitas vezes, atuam na ilegalidade ou fora da proteção social oferecida por instituições públicas (KREIN; PRONI, 2010).

Embora as trocas relacionais (econômicas e/ou sociais) entre mercadores e clientes nas ruas seja um fenômeno social antigo, os debates iniciais sobre a "informalidade" apareceram no final da década de 60 e início dos anos 1970 com a elaboração e publicação de relatórios pela Organização Internacional do Trabalho (OIT) referente à situação das perspectivas trabalhistas em países subdesenvolvidos da África e América Latina. Especificamente, em 1969 a OIT lançou o Programa Mundial de Emprego (PME) cujo objetivo era "avaliar os efeitos, sobre o emprego e a distribuição da renda, das estratégias de rápido crescimento econômico empreendidas por países retardatários no processo de industrialização" (CACCIAMALI, 2000, p. 154-155).

A preocupação da OIT estava centrada na identificação dos problemas de geração de emprego nos países subdesenvolvidos e nas questões de justiça social e exclusão social. Esses fatores aumentavam diante do desemprego vigente, da baixa remuneração dos ocupados e da precarização das relações trabalhistas e sociais (KREIN; PRONI, 2010).

$\mathrm{Na}$ visão de Cacciamali (2000), os resultados das avaliações feitas pelo PME nos países subdesenvolvidos mostraram que os processos de crescimento econômico substitutivo de importações, rápido e intensivo em capital não foram suficientes para garantir ofertas de trabalho à população economicamente ativa. Pelo contrário, o efeito ocasionado culminou no aumento de atividades organizadas em pequenas escalas. Assim, começaram a aparecer grupos, pessoas e setores sociais de base familiar compostos por trabalhadores de rua, prestadores de serviços urbanos, trabalhadores autônomos, por conta própria ou auto emprego que não se enquadravam em formas de trabalho típicas do mundo capitalista (DUR ÃES, 2009; FILGUEIRAS; DRUCK; AMARAL, 2004).

Emerge, portanto, um novo formato de atividade que utiliza como critério a forma de organização da produção, ou seja, "são informais os trabalhadores das unidades de produção não tipicamente capitalistas no interior do capitalismo, sendo que o conjunto destas unidades de produção compõe o setor informal" (PAMPLONA, 2013, p. 228).

No chamado setor informal, as unidades produtivas não são totalmente capitalistas por que não há uma separação clara entre capital (donos do negócio) e produção (força de trabalho) e o lucro não é o objetivo principal. O fator essencial a ser preservado é a manutenção e sobrevivência da família e, por último, a preocupação com a manutenção do negócio ou retorno financeiro (PAMPLONA, 2013; DUR ÃES, 2009; FILGUEIRAS; DRUCK; AMARAL, 2004). Segundo a OIT (1993) o setor informal é formado por unidades produtivas de bens ou serviços para gerar emprego e renda. De forma operacional, possui nível baixo de organização, pouca ou nenhuma divisão entre mão de obra e fatores de produção. Quando da presença de relações trabalhistas, são baseadas em emprego ocasional, no parentesco ou nas relações pessoais e sociais, ao invés de acordos contratuais com garantias formais.

É notório que as tentativas de desenvolvimento de políticas econômicas e sociais eficazes pelos países retardatários no processo de aceleração de crescimento trouxeram reflexos nas formas de concepção do trabalho. Nos anos 80, o discurso girava em torno de que para se alcançar a modernidade era necessário passar por reformas estruturais no âmbito das privatizações e da desregulamentação dos mercados e do trabalho. 
Dessa forma, para Costa (2010), o problema da informalidade passou a ser considerado com foco na perda da centralidade, da força do setor secundário para empregabilidade e do crescimento do setor de serviços na absorção da força de trabalho. A OIT se reposicionou sobre a questão da informalidade em 1991, na $78^{a}$ Conferência Internacional do Trabalho. O momento histórico era o da transição de economias socialistas para o modelo de abertura econômica e, dessa forma, a preocupação girava em torno dos países em que havia o predomínio do trabalho informal (KREIN; PRONI, 2010). Nessa transição de mercado, houve uma perda do dinamismo das formas de emprego com surgimento de novo padrão. Esse provocou a geração de poucos trabalhos, mal remunerados e desprotegidos (BORGES, 2007).

Diante do cenário dos anos 90, a OIT estabeleceu uma definição consensual e compatibilizou critérios de mensuração a ser utilizados pela maioria dos países. Para tanto, foram estabelecidos dois tipos de classificação: "empreendimentos unipessoais ou familiares; e microempresas com trabalho assalariado" (BOUÇAS, 2015, p. 31). Essa classificação perdurou até 2002, quando a OIT adotou a terminologia economia informal. Segundo Pamplona (2013) o novo conceito basicamente unifica dois termos: setor informal e emprego informal.

Um terceiro conceito mais recente foi proposto por Cacciamali (2000) no qual aborda o termo informal com uma amplitude maior, denominado de processo de informalidade. A justificativa está pautada na necessidade de se levar em consideração aspectos como as mudanças estruturais em andamento na sociedade e na economia que interferem direta ou indiretamente nas formas de trabalho.

Observa-se que os debates teóricos sobre o tema são amplos e passaram a ser feitos sob diferentes perspectivas que não necessariamente se contradizem, apenas diferenciam o posicionamento dos diversos interlocutores. Para Krein e Proni (2010), o trabalho informal é pautado em duas vertentes: "o trabalho que se manifesta nos setores não estruturados da economia (urbana e rural) e aquele que é executado de maneira informal nos setores organizados da economia capitalista" (KREIN; PRONI, 2010, p. 12).

Diante da diversidade de concepção teórica existente, Pamplona (2013) propõe que o termo "informal" pode assumir três marcos conceituais. O primeiro marco caracteriza informal como setor informal o qual enfatiza a natureza do processo e unidade produtiva, a baixa produtividade e a pobreza. $\mathrm{O}$ segundo pontua informal como economia informal, sendo, nesse contexto, enfatizado o problema da ocupação, da baixa qualidade do emprego e da falta de proteção social. O terceiro define o informal como processo de informalidade que prioriza as mudanças estruturais da economia e da sociedade. Essas (re)criam formas do informal limitando a regulação estatal da atividade econômica e estimulando a não aceitação de regulação por parte dos agentes produtivos.

Os marcos teóricos apresentados remetem à inquietação para se conhecer a realidade vivenciada por trabalhadores de ruas do Brasil, em especial, se os mesmos conseguem desfrutar das oportunidades do acesso aos microcréditos diante da informalidade dos seus negócios.

\subsection{Cenários do trabalho informal praticado nas ruas}

No contexto brasileiro, o trabalho nas ruas é considerado como uma atividade antiga que vem sendo praticada desde os períodos coloniais. Segundo Durães (2002) tais práticas de trabalho remontam dos séculos XV e XVI, época dos descobrimentos, na qual já havia carregadores de mercadorias, bens e pessoas que atuavam nos portos e vias públicas das capitais litorâneas de Salvador, Recife e Rio de Janeiro. Por muito tempo, o que mais se viu pelas ruas e calçadas das cidades foram escravos africanos e mestiços vendendo comidas 
típicas (quitandeiras) e/ou trabalhando como carregadores. Eles ficavam andando de um lado para o outro da cidade levando mercadorias ou prestando serviços. Além disso, tinha também aqueles que se aglomeravam em ponto fixos - denominados "cantos", a espera de clientes (DURÃES, 2002).

Com o passar dos anos, termos como "ambulantes" e "camelôs" emergiram e acabaram se consolidando. A atuação desses informais nos contextos urbanos foi crescendo e o que parecia ser um problema estrutural transitório e insólito com grande expectativa de pulverização pela sociedade, acabou tomando proporções maiores com reflexos não só em países emergentes como o Brasil, mas também no seio das grandes economias globais.

Consoante Rodrigues (2008), a atividade de camelô tem sua origem na venda ambulante. A diferença é que os camelôs fixam suas atividades em um mesmo local e os ambulantes não. Entre os camelôs, existe uma exígua diferenciação entre os que são legalizados e os clandestinos. Aqueles que trabalham ilegalmente são reconhecidos como toreros e vivem se esquivando das fiscalizações. Já os considerados regulares possuem autorização expedida pela prefeitura para trabalhar em shoppings populares (CARRIERI; MARANHÃO; MURTA, 2009). No tocante ao vendedor ambulante, tem-se o seguinte conceito:

[...] trabalhador normalmente autoempregado que vende diretamente ao consumidor (varejo) produtos diversos (normalmente miudezas e mercadorias de mais baixo valor), ou presta serviços (normalmente de alimentação), em vias e logradouros públicos (ruas, calçadas, praças, jardins, etc.), fora de lojas, em postos, fixos ou móveis, ou de forma itinerante levando sua mercadoria junto ao corpo, com ou sem permissão oficial (PAMPLONA, 2013, p. 230).

$\mathrm{Na}$ literatura internacional, os ambulantes são classificados como comerciantes de rua ou street vendor. Estão inclusos nessa categoria todos aqueles que vendem produtos ou prestam algum tipo de serviço em espaços públicos (HORN, 2009). Para Bhowmik (2005), um vendedor de rua é caracterizado como aquela pessoa que vende seus produtos fora de construções físicas, ou seja, são comerciantes que usam os espaços públicos e privados (ruas, calçadas e faixas de pedestres) de forma fixa ou itinerante.

O comerciante de rua também carrega uma verossimilhança com a figura do empreendedor ainda mais diante da proliferação de incentivos aos indivíduos para que se lancem no mercado como donos do seu próprio negócio. Todavia, são agrupados na categoria de "empreendedores por necessidade", isto é, "aqueles que respondem que a criação do negócio foi efetivada pela falta de outras possibilidades para geração de renda e de ocupação" (GEM, 2010, p. 11). Embora inseridos numa economia capitalista, parte-se de uma lógica de sobrevivência não voltada para obtenção de lucros por causa da baixa concorrência efetiva e o desempenho de atividades de baixa produtividade. Como apontam Corsino e Mariani (2019, p. 110), o empreendedorismo deve ser compreendido como um fenômeno social e econômico. Os autores entendem que instituições informais e formais podem "legitimar o empreendedorismo como uma atividade de valor social, ou ao contrário, limitar e desencorajar o potencial empreendedor".

Embora não se tenha como objetivo esgotar as discussões sobre as variações conceituais entre os termos comerciantes de rua, empreendedor por necessidade, vendedor ambulante e camelôs, os conceitos aqui elencados visam mostrar que tais ofícios são similares e se complementam, uma vez que ao atuar nas ruas, esses trabalhadores informais territorializam os espaços de passagem, transformando-os em locais de trabalho e fonte de renda ao utilizar estratégias flexíveis e adaptadas aos consumidores de rendimentos baixos.

De acordo com Silva (2003), grande parte dessa nova informalidade provém de um agrupamento majoritário de pessoas advindas de grupos sociais pauperizados e sem 
qualificação que acabam encontrando nesse tipo de trabalho uma forma de garantir a sobrevivência e complementar renda. Esses são alguns daqueles que SOUZA (2012) nomeou de "batalhadores brasileiros", ou seja, grupo integrante da ralé brasileira que luta para sobreviver através das suas atividades econômicas. São pessoas hostilizadas por andarem fora dos parâmetros legais devido à comercialização de mercadorias e prestação de serviços sem anuência dos órgãos públicos. Além disso, muitos deles são estigmatizados como contrabandistas, mafiosos, vagabundos e tais estigmas operam como instrumento ideológico para inferiorizá-los, colocando-os à margem e exclusão (GOFFMAN, 1999). O contexto descrito contribui para a emergente necessidade de vitalização da humanidade, sendo considerada como fator essencial para o desenvolvimento da sociedade, da economia e da evolução das civilizações humanas (MINEIRO; SOUZA; VIEIRA; CASTRO; BRITO, 2018).

\subsection{O Microcrédito}

Os trabalhadores de rua também necessitam de fontes de recursos econômicos para realizar suas atividades. Uma possibilidade para essa obtenção seria o acesso aos programas de microcréditos ao invés dos créditos tradicionais. O crédito dado a pessoas físicas ou jurídicas é caracterizado pela entrega de um valor mediante promessa de o pagamento ser efetuado num momento futuro (SILVA, 2006). Sua intermediação geralmente é feita por bancos comerciais, financeiras, cooperativas de créditos, sociedades de crédito e associações, sendo a sua forma mais tradicional através dos bancos públicos. Tais instituições financeiras assumem o risco de obtenção ou não do valor de empréstimo disponibilizado por fornecerem crédito ao tomador.

Por causa dos riscos imanentes, os bancos vão criando critérios que acabam se transformando em barreiras para tipos específicos de trabalhadores, por exemplo, micro e pequenos empreendedores. A maioria acaba encontrando dificuldade na obtenção do crédito pela falta de garantias reais nas operações.

Ampliando essa concepção, os estudos de Munhoz e Nassif (2012) consideraram relevante as variáveis comportamentos inovadores e criativos com a capacidade de empreender. Na nossa concepção, os trabalhadores de rua demonstram ter criatividade e podem inovar seus negócios próprios. Todavia, eles carecem de visibilidade social, de oportunidades provenientes das instituições públicas e privadas. Para exemplificar, a inclusão financeira deveria atender aos trabalhadores de ruas.

As políticas de microcrédito surgem, então, como possibilidade de amenizar o problema da disponibilidade de crédito aos pertencentes de classes sociais baixas. Aparecem como fonte alternativa de recursos não só para os trabalhadores formais, mas também para os informais, objetivando, justamente, o combate à pobreza e exclusão social (SOUZA JÚNIOR, 2012). Coutinho (2008) assevera que nos países em desenvolvimento, os programas de microcréditos e de apoio às micro e pequenas empresas inseridas no setor informal são percebidos por gestores governamentais apenas como uma política social, sem ênfase nos aspectos econômicos que envolvem obrigações pecuniárias. A autora faz um alerta sobre a necessidade de formalização das empresas e também enfatiza a importância de se obedecer à legislação trabalhista e ambiental. O não cumprimento desses mecanismos acaba se tornando um grande desafio para suprimir a pobreza e gerar mais empregos e renda (COUTINHO, 2008).

O microcrédito é considerado como a principal atividade inserida dentro das microfinanças e consiste em empréstimos de pequeno valor fornecidos por instituições bancárias não tradicionais a microempreendedores ou pertencentes à economia informal para o desenvolvimento do seu negócio (SOARES; MELO, 2008; MARTINS et al. 2002). 
Mesmo com a difusão de programas de microcréditos em diversos países, muitos públicos da sua focalização não conseguem ter acesso devido ao elevado risco de inadimplência da operação. Soma-se a esses aspectos: "taxas de juros elevadas, cronograma de reembolso restritos, empréstimos insuficientes, falta de supervisão após o empréstimo e falta de educação e habilidades entre beneficiários do microcrédito" (ALI et al., 2017, p.13).

A fim de amenizar problemas como os já descritos, o Grameen Bank de Bangladesh criou um sistema de grupos solidários que integra grupos de tomadores em que todos se tornam responsáveis pelo pagamento de cada membro, ou seja, caso um indivíduo não pague, os outros arcam com a despesa. Outra política adotada é que os empréstimos são disponibilizados a partir do histórico positivo de pagamento, configurando-se como fator essencial para novos financiamentos com valores maiores (NERI, 2010).

\subsection{A focalização do microcrédito e sua operacionalização no Brasil: perfil dos tomadores de microcréditos no Brasil}

No Brasil, a focalização do microcrédito visa atender às pessoas que possuem características de empreendedores. Essa é uma das causas da prevalência do microcrédito produtivo e orientado em detrimento de outros créditos. As abordagens de pesquisas sobre microcréditos e microfinanças são bastantes críticas no que tange às metodologias e o alcance do público-alvo que devem ser adaptados pelas instituições financeiras tradicionais para atingir o objetivo de inclusão social financeira e desenvolvimento (SANTOS; D 'SOUZA; LIMA, 2013).

Morduch (1999) afirma que as microfinanças têm como finalidade disponibilizar serviços financeiros aos mais desfavorecidos, possibilitando-lhes rendimento e emprego por meio do desenvolvimento de pequenos negócios. Dentre esses desfavorecidos estão inclusos os trabalhadores de rua, cuja maioria é proveniente da situação de pobreza, sendo, portanto, considerados como trabalhadores e batalhadores.

No cenário de inclusão financeira e altas taxas de desemprego, uma estratégia política adotada é a abertura de créditos de pequenos valores para empreendedores que, na maioria das vezes, buscam garantir a sobrevivência do seu negócio. Em paralelo com a abertura de crédito e inclusão financeira, a política econômica incentiva as pessoas a consumirem mais. Assim, o crédito concedido possibilita ao mesmo tempo maior renda e maior consumo. $\mathrm{Na}$ visão de Pinho, Vasconcelos, Ituassu e Goulart (2016), a inclusão financeira precisa ser vista além da necessidade de políticas públicas, para isso requer atenção de governos, de empresas e da diretriz de rentabilidade no campo financeiro.

Portanto, o microcrédito tem como alvo estimular a produção e o consumo, em consonância com a dominação e manipulação de pequenos empreendedores; escravos do sistema capitalista financeiro. Isso se dá por meio da assimetria de informações e do novo nicho mercadológico das instituições financeiras. Existem desafios que representam as falhas das instituições de serviços microfinanceiros e que afetam a realidade do público-alvo, as taxas, o aumento da capilaridade e a segurança social (MORDUCH, 1994). Fraga, Teodósio e Mswaka (2019) dissertam que tais desafios vão ao encontro da falta de harmonia entre objetivos de instituição financeira e público-alvo. A sintonia dos objetivos e das focalizações dos microcréditos contrariam os objetivos tradicionais das microfinanças mundiais voltadas para a emancipação das pessoas em situação de pobreza de forma a propiciar condições econômicas para o desenvolvimento das capacidades humanas.

Nessa vertente, as instituições financeiras de microcréditos possuem formas distintas das tradicionais para conceder os valores. Desse modo, a focalização dos microcréditos possui como recorte de metodologia e acesso ao crédito a formação de grupo de garantia solidária. $\mathrm{O}$ mesmo se caracteriza, em especial, pelos laços de solidariedade e confiabilidade que são 
garantias intangíveis e que podem excluir pessoas no acesso ao crédito e assim criar uma estratificação de classe dentro de uma comunidade.

Gonzalez, Vidal e Christopoulos (2013) mencionam no campo da focalização das microfinanças a metodologia da proximidade. Essa utiliza os agentes de crédito como intermediários nas relações institucionais que desenvolvem funções de reconhecimento de nichos, prospecção e acompanhamento de clientes, etc. Nessa operacionalização tem-se o profissional do agente de crédito. Caracterizam-se por uma proximidade física e vínculo estreito com a comunidade e os clientes (MORDUCH, 1999).

Sama e Casselman (2013) citam como exemplos de negócios de proximidade com consumidores, agregação de demanda e empreendedorismo por incubação. Essas vertentes podem ser oportunidades para trabalhadores de ruas informais terem acesso ao microcrédito e alavancar seus pequenos negócios. Na maior parte não são negócios e sim formas de trabalho e sobrevivência que se mantêm escravizadas aos poderes econômicos, políticos e financeiros.

Abramovay (2004) alerta para a relevância do crédito como instrumento de promoção de atividades produtivas em consonância com as necessidades e condições de vida de diversos trabalhadores que diante do desemprego estrutural, veem no negócio a principal fonte de recurso para a família e não propriamente para expandir e ter lucratividade e competitividade na sua atividade. $\mathrm{O}$ autor mencionou, em relação às operacionalizações das instituições financeiras, os desafios de propiciar disponibilidade imediata de recursos financeiros, quantidade suficiente, taxas e preços realísticos para o público-alvo dos microcréditos. São desafios que requerem inovação para as microfinanças efetivar na prática seu objetivo de inclusão social.

Esses atributos são instrumentos de promoção de atividades produtivas e de melhoria da qualidade de vida de empreendedores de sobrevivência. Um exemplo no Brasil e referência na América Latina é o Banco do Nordeste no Brasil com o programa Crediamigo. Segundo a teoria no campo das microfinanças mundiais, a modalidade núcleo do Crediamigo é o microcrédito produtivo direcionado para microempreendedores formais ou informais. Enfatiza que os mesmos devem ser pobres, mas pobres ativos que querem ter negócio próprio e que possuem capital social relacional que darão garantias aos créditos concedidos.

Nesse sentido, Abramovay (2012) caracteriza a existência de uma nova economia por meio da cooperação social. O objetivo é ampliar a participação dos trabalhadores e de comunidades nos processos de criação de riqueza e de inovar as formas de trabalho, entre elas inclui-se o trabalho informal. Essas diversidades de formas informais de negócios aumentam a complexidade operacional para atuação das instituições de microfinanças. Torna-se essencial as metodologias específicas para atingir o público-alvo dos microcréditos e satisfazer a necessidade de insumos de capitais que promovam a transformação da nova economia e do trabalho face ao desenvolvimento sustentável para todos, pautado na ética dos diversos agentes dos mercados, das políticas sociais e da sociedade.

No Brasil, diversas variáveis dificultam a ampliação dos microcréditos. Entre elas, Chaves (2011) argumentou a pouca presença das instituições privadas no setor microfinanceiro. Fator que requer maior participação do governo. Segundo o autor, a solidez e regulamentação do sistema financeiro nacional se tornam seletivos e excludentes, sendo contrários os objetivos de inclusão social e capacitação das pessoas que se aventuram nos negócios para indiretamente remunerar o setor financeiro e sua capilaridade.

Nessa contextualização de focalização das microfinanças/microcréditos no Brasil percebeu-se que houve o surgimento do que diversos pesquisadores chamaram de "Nova Classe Média Brasileira". Entre eles, destaca-se Souza $(2009,2012)$ que de forma crítica a Neri (2010) evidencia o perfil das pessoas da suposta melhoria de classe; pessoas que na realidade vivem em situação de pobreza. Alerta que é mais uma forma de manipulação e de 
subordinação e que no Brasil a reprodução de desigualdades se dá além dos capitais econômicos, na ausência e limitação ao capital cultural e social.

Torna-se preponderante a disponibilização de capital econômico e capital financeiro por parte das microfinanças/microcréditos, sendo este último considerado a base para a identificação e alavancagem dos ativos dos trabalhadores de negócios próprios para a sobrevivência. A integração do capital econômico, financeiro, social e simbólico requerem estruturas de oportunidades que propiciam acesso a bens, serviços e atividades que influenciam o bem-estar das famílias e facilitam a utilização de recursos próprios ou forneçam novos recursos com características de utilidade para a mobilidade e integração social (KATZMAN, 2000; FRAGA; TEODÓSIO; MSWAKA, 2019). Dessa forma, a inclusão aos serviços bancários requer, a priori, a prática de ética nos negócios de forma digna e transparente, quebrando a assimetria informacional e as amarras financeiras para reter o cliente e ser parceira nos resultados dos empreendimentos de sobrevivência.

Souza $(2009,2012)$ descreveu que a representação da nova classe média se dá pelos trabalhadores-batalhadores, aqueles provenientes da ralé estrutural. A crítica de alguns pesquisadores em relação a essa nova classe média está relacionada à condição precária de trabalho, salário e moradia e sem mudança de habitus e de classe. Esses fatores são encontrados na vida dos trabalhadores de rua. Na atividade dos mesmos podem ser encontradas as características da ilusória nova classe, entre elas o aumento e a necessidade de afirmação do indivíduo e o aumento das potencialidades para negócios.

A Ralé tem como característica principal a força de trabalho, segundo estudos de Souza $(2009,2012)$, a estratégia é transformar a necessidade de vida em ação produtiva. Todavia, nem todas as pessoas possuem essa estratégia e feeling empreendedor, visto que a consciência de afirmação e valorização se faz por meio de atributos cognitivos e psicossociais. Tais fatores podem estar ausentes nas pessoas da ralé (SOUZA, 2009).

Os debates brasileiros da nova classe média, neste artigo, são representados por Abramovay (2012); Souza e Lamounier (2010); Neri (2010), Pochmann (2013, 2014). As discussões críticas envolvem a complexidade de classes e suas caracterizações específicas no contexto macro social. Perpassam pelos fatores educacionais como essencial à inserção ocupacional em empresas e no desenvolvimento de negócios próprios e novas formas de trabalho; isso envolve a capacitação. De forma complementar, os eixos são o mercado, a produção e o consumo que deveriam ser integrados ao eixo político do bem-estar social e à realidade de pequenos empreendimentos, entre eles a dos trabalhadores informais de rua.

Ao considerar a nova classe média como o motor de expansão da economia, Abramovay (2004) questiona a sua sustentabilidade e manutenção no médio e longo prazo. Conforme Pochmann (2013, 2014), nesse segmento está a classe trabalhadora que, incentivada pelo consumismo, está imbricada no sentimento de pertencer a uma classe melhor, tendendo ao individualismo. $\mathrm{O}$ autor retrata a composição da nova classe média por mais pessoas empregadas, porém não necessariamente em condições adequadas de trabalhos, salários justos e dignos (POCHMANN, 2013, 2014).

Souza (2012) confirma a composição da nova classe média por novos trabalhadores decorrentes do desemprego estrutural. Nessa classe há a ausência ou pouco capital social e cultural para os trabalhadores batalhadores. Por outra vertente, Neri (2010) argumentou que as pessoas da nova classe média aumentaram seus consumos e suas rendas, e isso significa melhores condições de vida. Todavia, segundo Souza (2012), há um discurso economicista neoliberal nessa visão de Neri. Finaliza-se esse tópico recorrendo a Pochmann (2014, p. 69) "Nova Classe Média se destaca na elevação de índices de mão de obra que migraram do setor primário para o setor terciário nos últimos anos".

Outros aspectos da nova classe média são a necessidade de economia emocional e atributos pessoais para o trabalho produtivo, a competitividade e a inserção financeira 
(SOUZA, 2012). Com base nos mesmos, Souza $(2009,2012)$ classificou os batalhadores da nova classe média em duas classes: a dos trabalhadores e a dos empreendedores. São características da primeira, entre outras, família estruturada, satisfação das necessidades imediatas e bastante disposição para o trabalho. Essa disposição tem atributos de esforço físico, honestidade, priorização da dignidade. Outra característica é a habilidade primária para cálculo e administração.

A segunda classe possui elementos diferenciais e que são denominados de disposições secundárias. Suas principais características além das dos trabalhadores são: disposição para cálculo, autossuperação e liderança (SOUZA, 2012). Nesse contexto, a nova classe média envolve a capacidade de incorporação de conhecimento e está inserida na abordagem sociológica do "habitus" (SOUZA, 2009, p. 335).

Segundo Sen $(1981,2000)$ o habitus refere ao conjunto de características humanas que definem o modo de conduzir a vida. Indivíduos socializados, num contexto de habitus primário, incorporam as formas de pensar e agir necessárias para alcançar qualificação profissional, autorrespeito e estima social. Assim, quando as pessoas da ralé conseguem atingir a classe social dos batalhadores, a maioria busca no crédito uma possibilidade de iniciar, melhorar ou expandir seu "empreentrabs - empreendimento de trabalho para sobrevivência” (FRAGA; TEODÓSIO; MSWAKA, 2019).

No contexto macro brasileiro, Neri $(2010,2017)$ advogou a ruptura da violência simbólica econômica contra as classes dos batalhadores. A causa desse rompimento pode ter sido a realidade de que os batalhadores são agentes econômicos e sociais na promoção do desenvolvimento do país (SOUZA, 2012). Como exemplo, existe o programa Crediamigo do Banco do Nordeste, cujo objetivo é a inclusão financeira das pessoas e o acesso ao crédito. Caracteriza-se pela oferta dos empréstimos de baixo volume em curtos intervalos de tempo.

Segundo Souza (2012), o Crediamigo contempla as classes dominadas e desfavorecidas na hierarquia social da economia e do trabalho, desde que se diferenciaram na expectativa de serem trabalhadores autônomos. Logo, eles devem ter disposições para cálculo, administração, esforço de tempo e mão de obra, bem como possuir flexibilidade relacional. No campo de acesso ao crédito, prevalece a assimetria da informação, custos altos de transações, baixos volumes de negociação, complexidade operacional. São fatores que desafiam as instituições financeiras e as políticas de inclusão a superá-los por meio de metodologias e estratégias específicas voltadas ao público-alvo proveniente da situação de pobreza (GUERRERO, 2000).

Estudiosos como Nichter, Goldmark e Fiori (2002) demonstraram a descrença de o microcrédito ser suficiente para gerar emprego e renda. Apontam a insuficiência do mesmo para retirar as pessoas da pobreza e satisfazer suas necessidades básicas, mesmo com o incentivo para trabalhar em seus próprios negócios. No caso de empreendedores informais provenientes da situação de pobreza existem dificuldades para o acesso tradicional aos créditos pelo sistema bancário. Como exemplos têm-se a precariedade dos negócios, as condições da situação de pobreza, a exigência de requisitos pelo tradicional sistema financeiro para conceder financiamento (CARVALHO et al., 2009; ABRAMOVAY, 2004).

Outra dificuldade é a capacidade dos empreendedores informais fazerem a gestão separada dos ativos do negócio com os bens e direitos familiares. $\mathrm{O}$ argumento é que no cotidiano, o objetivo fim dos negócios não é a atividade principal e sim a sustentação e sobrevivência do núcleo familiar (FREITAS; RIBEIRO, 2009).

Moser e Gonzalez (2015) advogam que uma abordagem pouco explorada nos estudos de microfinanças é a adaptação dos serviços ao nível do cliente. Enfatizam a existência de poucos estudos que combinam microfinanças e adaptações. Uma dessas adaptações é em relação aos trabalhadores de rua, configurando, portanto, numa lacuna para a condução de 
novas pesquisas que buscam identificar como e quais são os recursos e condições dos trabalhadores de rua informais. Como eles são vistos pelos mecanismos dos microcréditos.

A complexidade e diversidade de negócios que podem utilizar as microfinanças explicitam que esse campo financeiro envolve mecanismos de mercado, apoio estratégico do Estado e iniciativas comunitárias. A estruturação de serviços financeiros para trabalhadores/batalhadores de baixa renda, formalizada ou não requer sustentabilidade social, ambiental e financeira (PARENTE, 2002). Na realidade, o foco da inclusão financeira são as pessoas pobres e que tenham um negócio próprio.

De acordo com Passos et al. (2002), os programas de microcréditos alcançam pouco as pessoas mais pobres com carência de aptidões para o negócio e até ausência de condições físicas. A afirmativa possui três argumentos. No primeiro caso, o crédito abre oportunidades de autoemprego para os pobres, porém na situação dos mais pobres, as oportunidades são mais limitadas e os riscos são razoavelmente mais altos e geram a autoexclusão; os menos pobres podem excluir os mais pobres, devido ao risco que representam para a formação e manutenção do grupo solidário; a profissionalização do gerenciamento dos programas cria estruturas de incentivos com hierarquias e privilégios ao recebimento de bônus e promoções, isso leva ao incentivo da concentração em outros grupos dos menos pobres.

Gonzalez e Moser (2016) fazem um chamamento quanto aos cuidados com os microcréditos na vida das pessoas em situação de pobreza. Em alguns casos, o microcrédito pode onerar e aumentar o peso da dívida dos clientes pobres reduzindo a capacidade de adaptação dos mesmos ao sistema financeiro. Corroborando com a mesma visão, Hulme e Mosley (1996) concluem em suas pesquisas que o impacto de um empréstimo sobre a renda de um mutuário está relacionado ao nível de renda.

\subsection{A pesquisa: realidade dos trabalhadores de ruas $e$ suas oportunidades de acesso financeiro}

No Brasil, a focalização das microfinanças encontra-se registrada nos documentos internos das instituições financeiras que disponibilizam tais serviços. Assim, determinados dados sobre o perfil dos clientes e processos internos para aprovação do microcrédito acabam se tornando de difícil acesso por serem considerados informações sigilosas. Tal circunstância acaba criando barreiras que dificultam a identificação das pessoas que utilizam os microcréditos, dentre elas, os trabalhadores de rua.

Diante das dificuldades do acesso a esses dados primários, realizou-se em julho de 2019 uma pesquisa secundária nos sites institucionais dos principais bancos públicos que disponibilizam microfinanças e microcréditos a fim de tentar identificar qual o público-alvo desses programas. A escolha dos bancos foi realizada com base na classificação do SEBRAE (2018) que elenca as instituições mais conhecidas no Brasil e basilares no fomento, sendo elas: a Caixa Econômica Federal (CEF), o Banco do Brasil (BB), o Banco da Amazônia (BAM) e o Banco do Nordeste (BNB).

Para Silva (2003) os atuantes informais persistem nessa atividade por que não há perspectivas de políticas de reintegração econômica. Portanto, permanece em atividade um exército de reserva estagnado e em expansão com grandes possibilidades de reinserção. Os dados coletados mostraram que o Banco do Nordeste é a única instituição financeira que menciona vendedores ambulantes como clientes tomadores de microcrédito do programa Crediamigo. Os segmentos atendidos pelo banco vão desde atividades ligadas à indústria e serviços até comércio, cujos ofícios descritos no site institucional são: ambulantes, vendedores em geral, mercadinhos, papelarias, armarinhos, bazares, farmácias, armazéns, restaurantes, lanchonetes, feirantes, pequenos lojistas, açougueiros, vendedores de cosméticos etc. (BNB, 2019). As demais instituições mencionam que o acesso está aberto para 
empreendedores formais (MEI ou ME) e informais compostos por indivíduo ou grupo solidário entre 3 a 10 pessoas, sem especificação se os trabalhadores de rua (ambulantes e camelôs) se enquadrariam.

Outro ponto que chama a atenção diz respeito ao apoio institucional inicial dado pelo banco. Na maioria prevalece a figura de um orientador ou agente de crédito que intermedia a operação, com exceção do Banco da Amazônia que não especifica. Esse personagem as sume um papel importante, pois sua análise do estabelecimento, documentação exigida e demais requisitos permite a liberação do microcrédito. A caixa Econômica dá um passo a frente ao focar nessa orientação ao cliente, disponibilizando material sobre gestão de negócios através dos orientadores e acesso à plataforma de ensino a distância desenvolvida para pequenos e microempreendedores. As principais informações coletadas foram compiladas e estão representadas (Quadro 1) abaixo:

\begin{tabular}{|c|c|c|c|c|c|}
\hline \multicolumn{6}{|c|}{ Quadro 1: Grupos e indivíduos contemplados pelas políticas de microcrédito } \\
\hline Banco & $\begin{array}{l}\text { Programa de } \\
\text { microfinanças }\end{array}$ & $\begin{array}{l}\text { Nome Produto } \\
\text { (microcrédito) }\end{array}$ & $\begin{array}{l}\text { Finalidade do } \\
\text { microcrédito }\end{array}$ & $\begin{array}{l}\text { Apoio } \\
\text { institucional }\end{array}$ & Público-alvo \\
\hline $\begin{array}{l}\text { Caixa } \\
\text { Econômica } \\
\text { Federal }\end{array}$ & Caixa Crescer & $\begin{array}{l}\text { Microcrédito Giro } \\
\text { Caixa Orientado }\end{array}$ & $\begin{array}{l}\text { Reformas, } \\
\text { comprar matérias- } \\
\text { primas ou fazer } \\
\text { outros } \\
\text { investimentos no } \\
\text { próprio negócio }\end{array}$ & $\begin{array}{l}\text { Orientador de } \\
\text { Crédito }\end{array}$ & $\begin{array}{l}\text { Empreendedores } \\
\text { formais (MEI ou } \\
\text { ME) e informais }\end{array}$ \\
\hline $\begin{array}{l}\text { Banco do } \\
\text { Brasil }\end{array}$ & $\begin{array}{l}\text { Não } \\
\text { especificado no } \\
\text { site }\end{array}$ & $\begin{array}{l}\text { Microcrédito } \\
\text { Produtivo } \\
\text { Orientado (MPO) }\end{array}$ & $\begin{array}{l}\text { Melhorar o fluxo } \\
\text { de caixa (capital } \\
\text { de giro), comprar } \\
\text { equipamentos, } \\
\text { móveis, } \\
\text { ferramentas, etc. }\end{array}$ & $\begin{array}{l}\text { Agente } \\
\text { especializado }\end{array}$ & $\begin{array}{l}\text { Pequenos } \\
\text { empreendedores }\end{array}$ \\
\hline $\begin{array}{l}\text { Banco do } \\
\text { Nordeste }\end{array}$ & $\begin{array}{l}\text { Não } \\
\text { especificado no } \\
\text { site }\end{array}$ & Crediamigo & $\begin{array}{l}\text { Capital de giro e } \\
\text { investimentos em } \\
\text { capitais fixos }\end{array}$ & $\begin{array}{l}\text { Agente de } \\
\text { microcrédito }\end{array}$ & $\begin{array}{l}\text { Empreendedores } \\
\text { individuais ou em } \\
\text { grupos solidários } \\
\text { atuantes no setor } \\
\text { informal (ex. } \\
\text { ambulantes e } \\
\text { vendedores em } \\
\text { geral) ou formal }\end{array}$ \\
\hline \multirow{2}{*}{$\begin{array}{l}\text { Banco da } \\
\text { Amazônia }\end{array}$} & \multirow{2}{*}{$\begin{array}{l}\text { Não } \\
\text { especificado no } \\
\text { site }\end{array}$} & $\begin{array}{l}\text { Amazônia } \\
\text { Florescer Urbano }\end{array}$ & $\begin{array}{l}\text { Capital de giro e } \\
\text { investimentos em } \\
\text { capitais fixos }\end{array}$ & $\begin{array}{l}\text { Não } \\
\text { especificado } \\
\text { no site }\end{array}$ & $\begin{array}{l}\text { Empreendedores } \\
\text { populares } \\
\text { informais }\end{array}$ \\
\hline & & $\begin{array}{l}\text { Amazônia } \\
\text { Florescer MEI }\end{array}$ & $\begin{array}{l}\text { Capital de giro e } \\
\text { investimentos em } \\
\text { capitais fixos }\end{array}$ & $\begin{array}{l}\text { Não } \\
\text { especificado } \\
\text { no site }\end{array}$ & $\begin{array}{l}\text { Microempreende- } \\
\text { dores individuais } \\
\text { formalizados nos } \\
\text { estados do } \\
\text { Maranhão e Mato } \\
\text { Grosso }\end{array}$ \\
\hline
\end{tabular}

Fonte: Dados da pesquisa, 2019.

As políticas de concessão do microcrédito listadas pelo Banco do Brasil assumem formato mais burocrático e restritivo para os tomadores, pois os pequenos empreendedores precisam: ser correntista do banco; ser empreendedor informal com renda mensal de até $\mathrm{R} \$$ 16,66 mil; ser microempreendedor individual (MEI) com faturamento até $\mathrm{R} \$ 81$ mil por ano ou microempresa que fatura até R \$ 200 mil por ano; apresentar garantia pessoal de terceiros (em alguns casos ela pode ser dispensada) e o endividamento no Sistema Financeiro Nacional 
(SFN) não pode exceder $\mathrm{R} \$ 80$ mil (BB, 2019). A imposição dessas regras acaba restringindo a contratação de um microcrédito, principalmente, dos trabalhadores de rua que não passariam pelo crivo normativo.

Outro banco que pontua também alguns requisitos obrigatórios é o Banco do Nordeste o qual enquadra algumas regras em nível individual e grupal, são elas: ser maior de idade; ter ou querer iniciar uma atividade comercial; ter faturamento de até $\mathrm{R} \$ 200$ mil ao ano; aval solidário para empréstimos em grupo que funciona como a garantia conjunta para o pagamento das prestações; garantia de coobrigado para empréstimos individuais.

No tocante aos valores de empréstimo, no geral, variam entre 100,00 a 15.000,00 reais com taxas de juros por volta de 2,3\% a 3,5\% a.m., variando de acordo com a política de cada banco. A documentação requerida para solicitação do microcrédito é bem simples. Bancos como Caixa Econômica e Banco do Nordeste exigem apenas: RG, CPF e comprovante de residência, sendo nos demais não especificado (CEF, 2019; BNB, 2019).

Pode-se inferir, a partir dos dados, que pouquíssimas instituições de caráter público oferecem microcréditos para trabalhadores de rua, especialmente ambulantes e camelôs. $\mathrm{O}$ enquadramento do cliente é geral e sem delimitação clara, não permitindo afirmar se de fato tais trabalhadores teriam acesso facilitado ou não ao microcrédito.

\section{CONSIDERAÇÕES FINAIS}

Os estudos sobre a informalidade encontrados na literatura mostraram que não há uma definição conceitual unívoca, assumindo, portanto, multiformas. Também, não há um consenso a respeito de quais agentes e tipos de atividades poderiam ser caracterizados como informais. Neste trabalho foi possível identificar alguns autores-chave de várias áreas da academia que mais discutem a temática e, com isso, perceber que o assunto carece de mais estudos e aprofundamento, em especial de pesquisas qualitativas por meio de entrevistas e in loco.

Os resultados da pesquisa revelaram a complexidade que envolve a capilarização, as formas de proximidades, a focalização e as políticas de inclusão financeira dos trabalhadores de rua e seu acesso ao conjunto de políticas financeiras disponibilizadas por instituições públicas às pessoas de baixa renda.

O microcrédito foi apresentado, neste trabalho, como uma possibilidade para aqueles que não conseguem financiar suas atividades dentro do sistema tradicional da economia. Todavia, é notório que o acesso a esse benefício se esbarra em barreiras promovidas, na maioria das vezes, pelas políticas públicas sociais e pelas próprias instituições detentoras dessa forma de crédito, pois são criadas políticas burocráticas e evasivas que muitas vezes fogem do escopo original proposto pelo modelo original do microcrédito, prevalecendo a meta de lucratividade das instituições financeiras. Ademais, nas últimas décadas, as principais medidas políticas e econômicas que vêm sendo implantadas por gestores públicos estão voltadas para a sucumbência do problema da informalidade e não para desenvolver medidas eficazes que de fato ajudem tais pessoas a se reintegrarem ao mercado de trabalho.

Outro ponto relevante está ligado ao fato de que grande parte desses trabalhadores não toma conhecimento da existência desse tipo de crédito. Em alguns casos, por falta de acesso à cultura, socialização e ao sentimento de pertença, o que coloca entraves para que grande número de trabalhadores consiga se formalizar. O microcrédito pode ser uma opção de alavancar a vida desses trabalhadores, na tentativa de garantir-lhes não só um ganho econômico, mas também ganhos sociais, culturais e emocionais.

A realização de uma pesquisa empírica junto a trabalhadores de rua (ambulantes e camelôs) proporcionaria subsídios para validar e complementar os achados na presente pesquisa, principalmente, no que se refere à ciência dessa modalidade de empréstimo. Como 
uma das limitações deste artigo tem-se a escolha somente de instituições financeiras públicas e sem recorte regional delimitado. Desse modo, abre-se possibilidade de estudos que incluam também bancos privados e outras instituições públicas do Brasil.

\section{REFERÊNCIAS}

ABRAMOVAY, Ricardo (org.). Laços financeiros na luta contra a pobreza. São Paulo: FAPESP/Annablume, 2004.

ABRAMOVAY, Ricardo. Muito além da economia verde. São Paulo: Abril S.A, 2012.

ALI, Isahaque; HATTA, Zulkarnain A.; AZMAN, Azlinda; ISLAM, Shariful. Microfinance as a development and poverty alleviation tool in rural Bangladesh: a critical assessment. Asian Social Work and Policy Review, v. 11, n. 1, p. 4-15, nov. 2017. Disponível em: https://onlinelibrary.wiley.com/doi/abs/10.1111/aswp.12106. Acesso em: 29 jul. 2019.

BANCO DA AMAZÔNIA. Microcrédito. Disponível em:

https://www.bancoamazonia.com.br/index.php/microcredito. Acesso em: 03 de jul. de 2019.

BANCO DO BRASIL. Microcrédito Produtivo Orientado. Disponível em:

https://www.bb.com.br/pbb/sustentabilidade/negocios-sociais/microcredito-produtivoorientado\#l. Acesso em: 03 de jul. de 2019.

BANCO DO NORDESTE. Crediamigo. Disponível em: https://www.bnb.gov.br/crediamigo. Acesso em: 03 de jul. de 2019.

BHOWMIK, Sharit. Street vendors in Asia: a review. Economic e Political Weekly, v. 40, n. 22-23, p. 2256-2264, may./jun. 2005.

BORGES, Ângela. Mercado de trabalho: mais de uma década de precarização. In: DRUCK, G.; FRANCO, T. (Org.). A perda da razão social do trabalho: terceirização e precarização. São Pauto: Boitempo, 2007.

BOUÇAS, Rose Laila de Jesus. No olho da rua: trabalho e vida na apropriação do espaço público em Salvador / BA. 2015. 268f. Dissertação (Mestrado) - Programa de Pós-Graduação em Arquitetura e Urbanismo, Universidade Federal da Bahia, Bahia. Disponível em: https://repositorio.ufba.br/ri/handle/ri/20882. Acesso em: 01 set. 2018.

CACCIAMALI, Maria Cristina. Globalização e processo de informalidade. Revista Economia e Sociedade, Campinas, v.9, n.1, p.153-174, jun. 2000. Disponível em: https://periodicos.sbu.unicamp.br/ojs/index.php/ecos/article/view/8643124. Acesso em: 01 ago. 2018.

CAIXA ECONÔMICA FEDERAL. Programa Caixa Crescer. Disponível em: http://www.caixacrescer.com.br/CrescaComGente/QuemSomos. Acesso em: 03 de jul. 2019.

CARVALHO, Daniela Moreira; ARAÚJO, Eliane Aparecida; SALAZAR, Gérman Torres; FERREIRA, Roberto do Nascimento. Ênfase dos programas de microcrédito em sustentabilidade e viabilidade financeira: distanciamento do objetivo social de combate à 
pobreza? In: Anais: 47 Congresso da sociedade brasileira de economia, administração e sociologia rural (SOBER). Porto Alegre, RS. Porto Alegre, 2009.

CARRIERI, Alexandre de Pádua; MARANHÃO, Carolina Machado Saraiva de Albuquerque; MURTA, Ivana Benevides Dutra. Crítica ao manejo humano em Belo Horizonte. RAP, Rio de Janeiro, v. 43, n. 6, p. 1315-1342, nov./dez. 2009.

CHAVES, Sidney Soares. Diagnóstico e desafios do microcrédito no Brasil. Revista Desenbahia, n. 15, p. 193-228, set. 2011.

CORSINO, Michelle Oliveira do Espírito Santo; MARIANI, Milton Augusto Pasquotto. Ambiente institucional e empreendedorismo no brasil: inter-relações no século XXI. E\&G Economia e Gestão, Belo Horizonte, v. 19, n. 53, mai./ago. 2019

COSTA, Márcia da Silva. Trabalho Informal: um problema estrutural básico no entendimento das desigualdades na sociedade brasileira. Caderno CRH, Salvador, v. 23, n. 58. p. 171-190, jan./abr. 2010. Salvador: UFBA, 2010. Disponível em:http://www.scielo.br/scielo. php?pid=S0103-49792010000100011\&script=sci_abstract\&tlng=pt. Acesso em: 20 ago. 2018.

COUTINHO, Gisela Aguiar Soares. Reestruturação da cadeia produtiva têxtil em Valença-RJ. E\&G Economia e Gestão, Belo Horizonte, v. 8 n. 17, mai./ago. 2008.

DURÃES, Bruno José Rodrigues. "Trabalho Informal": um paralelo entre os trabalhadores de rua da cidade de Salvador no século XIX e no século XXI. Caderno CRH, Salvador, n. 37, p. 289-308, jul./dez. 2002. Disponível em:

https://portalseer.ufba.br/index.php/crh/article/view/18612. Acesso em: 03 out. 2018.

DURÃES, Bruno José Rodrigues. Trabalho de rua no Brasil e o processo de acumulação capitalista: o trabalhador gratuito. In: $6^{\circ}$ Colóquio Internacional Marx e Engels, 2009, Campinas. $6^{\circ}$ Colóquio Internacional Marx e Engels, 2009. Disponível em: https://www.ifch.unicamp.br/formulario_cemarx/selecao/2009/trabalhos/trabalho-de-rua-nobrasil-e-o-processo-trabalhador-gratui.pdf. Acesso em: 01 out. 2018.

EMPREENDEDORISMO NO BRASIL. Relatório executivo 2018 - GEM. Disponível em: https://datasebrae.com.br/wp-content/uploads/2019/02/Relat\%C3\%B3rio-Executivo-Brasil2018-v3-web.pdf .Acesso em: 04 out. 2019.

ESTATÍSTICAS SOCIAIS - IBGE. Desemprego cai para 11,6\%, mas informalidade atinge nível recorde. Disponível em: https:// https://agenciadenoticias.ibge.gov.br/agencianoticias/2012-agencia-de-noticias/noticias/23465-desemprego-cai-para-11-6-masinformalidade-atinge-nivel-recorde. Acesso em: 31 jan. 2019.

FILGUEIRAS, Luiz Antônio Mattos; DRUCK, Graça; AMARAL, Manoela Falcão do. O Conceito de informalidade: um exercício de aplicação empírica. Caderno CRH, Salvador, v. 17, n. 41. p. 211-229, maio/ago. 2004. Disponível em: https://portalseer.ufba.br/index.php/crh/article/view/18490. Acesso em: 02 out. 2018.

FRAGA, Marinette Santana; TEODÓSIO, Armindo dos Santos de Sousa; MSWAKA, Walter. Microfinance and poverty in developing countries: mudanças e desafios na sociedade 
brasileira contemporânea. In: Anais: 7th EMES International Research Conference on

Social Enterprise, Sheffield Hallam University, Reino Unido, 2019.

FREITAS, Ana Augusta Ferreira de; RIBEIRO, Rosa Cristina Lima. Análise segmentada da performance empreendedora de tomadores de microcrédito. Revista Econômica do

Nordeste, v. 40, n. 2, p. 249-261, abr./jun. 2009.

GOFFMAN, Erving. A representação do eu na vida cotidiana. Tradução Maria Célia Santos Raposo. 8. ed. Petrópolis: Vozes, 1999.

GONZALEZ, Lauro; VIDAL, Valentim; CHRISTOPOULOS, Tania. Microseguro oportunidades e restrições em um mercado emergente. Revista Pretexto, v. 14, n. 2, p. 20-39, abr./jun. 2013.

GONZALEZ, Lauro; MOSER, Rafael Magnus Barbosa. Green microfinance: the case of the Cresol System in Southern Brazil. Revista de Administração de Empresas, v. 56, n. 2, p. 242-250, mar./abr. 2016.

GRAMEEN BANK(GB). Banking for the poor. Disponível em: http://www.grameeninfo.org/monthly-reports-09-2017/. Acesso em: 03 de jul. de 2017.

GUERRERO, Javier Alvarado. As microfinanças e o crédito rural. In: Anais, Seminário internacional de microfinanças. Rio de Janeiro: BNDES, 2000.

HORN, Zoe Elena. No cushion to fall back on: the global economic crisis and informal workers. Women in Informal Employment: Globalizing and Organizing (WIEGO), 2009. Disponível em: http://www.wiego.com. Acesso em: 03 jan. 2019.

HULME, David; MOSLEY, David. Finance against poverty. London: Routledge, 1996.

INTERNATIONAL LABOUR OFFICE (ILO). 15th Internacional Conference of Labour Statisticians (15ª ICLS). Geneva, 1993. (Resolution II). Disponível em: http://www.ilo.org/public. Acesso em: 05 jan. 2019.

KATZMAN, Ruben. Notas sobre la medicion de la vulnerabilidad social: document de trabajo del IPES (aportes conceptuales n.2). Uruguai: IPES, 2000. Disponível em: https://repositorio.cepal.org/handle/11362/31545. Acesso em: 06 de jul. de 2019.

KREIN, José Dari; PRONI, Marcelo Weishaupt. Economia informal: aspectos conceituais e teóricos. Escritório da OIT no Brasil. - Brasilia: OIT, 2010. 1 v. (Série Trabalho Decente no Brasil; Documento de trabalho n.4). Disponível em: http://www.ilo.org/brasilia/publicacoes/ WCMS 227055/lang--pt/index.htm. Acesso em: 20 set. 2018.

MARTINS, Paulo Haus; WINOGRAD, Andrei; SALLES, Renata de Carvalho. Manual de Regulamentação das Microfinanças: Programa de Desenvolvimento Institucional. Rio de Janeiro, 2002.

MINEIRO, Andréa Aparecida da Costa; SOUZA, Donizete Leandro; VIEIRA, Kelly Carvalho; CASTRO, Cleber Carvalho e BRITO, Mozar José. Da hélice tríplice a quíntupla: 
uma revisão sistemática. E\&G Economia e Gestão, Belo Horizonte, v. 18, n. 51, set./dez. 2018.

MUNHOZ, Carlos Eduardo; NASSIF, Vânia Maria Jorge. O desvelar das competências dos intraempreendedores: um estudo exploratório em empresas de serviços. Revista Economia \& Gestão, Belo Horizonte, v. 12, n. 30, set./dez. 2012.

MORDUCH, Jonathan. Poverty and Vulnerability. The American Economic Review, v. 84, n. 2, p. 221-225, 1994.

MORDUCH, Jonathan. The microfinance promises. Journal of Economics Literature, v. 37, n. 4, p. 569-1614, dec.1999.

MOSER, Rafael Magnus Barbosa; GONZALEZ, Lauro. Microfinance and climate change impacts: the case of agroamigo in brazil. Revista de Administração de Empresas, v. 55, p. 4, n. 397- 407, july/aug. 2015.

NERI, Marcelo. The new middle class in Brazil: the bright side of the poor. Rio de Janeiro: Fundação Getúlio Vargas/Centro de Políticas Sociais, 2010.

NERI, Marcelo. Microcrédito, dinâmica empresarial e mudança de classe: o impacto do Crediamigo, 2017. Disponível em:

https://www.cps.fgv.br/ibrecps/Credi2/Credi2 2.0 Texto.pdf. Acesso em: 01 jun. 2019.

NICHTER, Simeon, GOLDMARK, Lara; FIORI, Anita. Entendendo as Microfinanças no Contexto Brasileiro. Brasília: BNDES, 2002. Disponível em: www.bndes.gov.br. Acesso em: 05 de jul. de 2019.

PAMPLONA, João Batista. Mercado de trabalho, informalidade e comércio ambulante em São Paulo. Revista Brasileira de Estudos de População, Rio de Janeiro, v. 30, n. 1, p. 225249, jan./jun. 2013.

PARENTE, Silvana. Microfinanças: saiba o que é um banco do povo. Brasília: Agência de Educação para o Desenvolvimento, 2002.

PASSOS, Alessandro Ferreira dos; PAIVA, Luis Henrique; GALIZA, Marcelo; COSTANZI, Rogério Nagamine. Focalização, sustentabilidade e marco legal: uma revisão da literatura de microfinanças. Mercado de Trabalho: Conjuntura e Análise. IPEA, 2002.

PINHO, Renato Lúcio; VASCONCELOS, Fernanda Carla Wasner; ITUASSU, Cristiana Trindade; GOULART, Íris Barbosa. E\&G Economia e Gestão, Belo Horizonte, v. 16, n. 43, abr./jun. 2016.

POCHMANN, Márcio. Mobilidade social no capitalismo e re-divisão internacional da classe média. In D. D. Barelt (Org.), A “nova classe média" no Brasil como conceito e projeto político. Rio de Janeiro: Fundação Heinrich, p. 156-170, 2013.

POCHMANN, M. O Mito da grande classe média: capitalismo e estrutura social. São Paulo: Boitempo Editorial, 2014. 
RODRIGUES, Ivanildo Dias. A dinâmica geográfica da camelotagem: a territorialidade do trabalho precarizado. 2008. 186f. Dissertação (Mestrado em Geografia) - Universidade Estadual Paulista, Presidente Prudente.

SAMA, Linda M.; CASSELMAN, Mitch Casselman. Profiting from poverty: ethics of microfinance in BOP. South Asian Journal of Global Business Research, v. 2, n. 1, p. 82103, 2013.

SANTOS, Ana Lucia Carvalho; D`SOUZA, Márcia Figueredo; LIMA, Gerlando Augusto Sampaio Franco de. Influência de características qualitativas nos indicadores contábeis de instituições microfinanceiras da América Latina e Caribe. Revista de Contabilidade e Controladoria, v. 5, n. 3, p. 83-97, set./dez. 2013.

SEBRAE NACIONAL. Tipos de organizações e forma de atuação em microfinanças. Disponível em: http://www.sebrae.com.br /sites/ PortalSebrae /artigos/tipos-de-organizacoese-forma-de-atuacao-em- microfinancas, ef59d53342603410

VgnVCM100000b272010aRCRD. Acesso em: jan. de 2018.

SEN, Amartya. Poverty and Famines Essay on Entitlement and Deprivation. Oxford: Clarendon press, 1981.

SEN, Amartya. Social exclusion: concept, application and scrutiny. Social Development Papers, 1. Asian Development Bank, Philippines, 2000.

SILVA, José Pereira da. Gestão e análise de risco de crédito. 5 ed. São Paulo: Atlas, 2006.

SILVA, Luiz Machado da. Mercado de trabalho ontem e hoje: informalidade e empregabilidade como categorias de entendimento. In: SANTANA, Marco Aurélio; RAMALHO, José Ricardo (Org.) Além da fábrica: sindicatos, trabalhadores e a nova questão social. São Paulo: Boitempo, 2003, p. 140-178.

SOARES, Marden Marques; MELO SOBRINHO, Abelardo Duarte. Microfinanças - O Papel do Banco Central do Brasil e a Importância do Cooperativismo de Crédito. 2. ed. Brasília: Banco Central do Brasil, 2008.

SOUZA, Amaury; LAMOUNIER, Bolivar. A classe média brasileira: ambições, valores e projetos de sociedade. Rio de Janeiro: Elsevie, Distrito Federal: CNI, 2010.

SOUZA, Jessé de. A ralé brasileira: quem é e como vive. Belo Horizonte: Editora UFMG, 2009.

SOUZA, Jessé de. Os batalhadores brasileiros: nova classe média ou nova classe trabalhadora? 2. ed. Belo Horizonte: Editora UFMG, 2012.

SOUZA JÚNIOR, Armando Araújo de; MORAES, Ana Flávia de Moraes. As práticas de microcrédito produtivo em uma empresa de reciclagem de papel do polo industrial de Manaus. Gestão e Sociedade, Belo Horizonte, v. 6, n. 14, p. 139-158, mai./ago. 2012. 